\title{
A structural equation modeling approach to examine the relationship between complexity factors of a project and the merits of project manager
}

\author{
Ahmad Makui ${ }^{a}{ }^{*}$, Pooria Moein Zadeha, Morteza Bagherpour ${ }^{\mathrm{a}}$ and Armin Jabbarzadeh ${ }^{\mathrm{b}}$
}

${ }^{a}$ Department of Industrial Engineering, Iran University of Science and Technology, Tehran, Iran ${ }^{b}$ Business School, McMaster University, Ontario, Canada

\section{CH R O N I C L E}

Article history:

Received: July 5, 2017

Received in revised format: October 10,2017

Accepted: December 5, 2017

Available online:

December 5, 2017

Keywords:

Structural equation modeling

Project Management

Project Complexity

Competency Standards

Project Manager

\section{A B S T R A C T}

\begin{abstract}
Nowadays, projects have become so widespread in the world that individuals and organizations are always involved in a variety of them. Recent advances in technology and fundamental changes in most scientific disciplines have had an essential impact on projects, and have made the nature and environmental conditions governing them to become more complex than before. With increasing complexity, the amount of information needed for project management increases. In general, the increasing complexity of projects is a growing source of project risks. It has been recognized that complexity affects the performance of a project and will be effective in its success. In this context, the traditional principles and practices of project management are no longer able to control the emerging complexity of projects. In addition, one of the key factors for the success of the projects is the appropriateness of the project manager's assignment. Many studies have been carried out in identifying the suitability criteria of the project manager and the methods of selecting the project manager. In most of these studies, the amount and type of complexity of the project are mentioned as factors influencing the design of an appropriate project manager. However, there has not yet been a specific approach for selecting the project manager with regard to the complexity of the project. Therefore, in this research, we try to investigate the relationship between the complexity of the project and the merits of the project manager by applying a structural equation modeling approach.
\end{abstract}

\section{Introduction}

Projects have become so widespread in the world today that individuals and organizations are always involved in a variety of projects. Almost all projects are distinguished from two main aspects: inherent characteristics and environmental conditions (Kahraman, 2008). Some of the inherent features, such as: type, range, duration, project budget and product; and environmental conditions such as location, stakeholders, risks, rules and policies of the project (Ahadzie et al., 2014). Rarely, can we find two projects that are completely identical. On the other hand, due to the special importance of various projects in human life and in the business of organizations, proper management of projects has always

* Corresponding author. Tel : +982177240129

E-mail address: amakui@iust.ac.ir (A. Makui) 
been of great interest for researchers and executives (Lin, 2010). Activists in this field are always looking for techniques and methods to manage various projects and succeed in achieving predetermined goals of projects. These efforts have led to the development of various project management standards and different methods for evaluating and analyzing project characteristics.

On the other hand, recent advances in technology and fundamental changes in most scientific fields have also affected projects, and have made the nature and environment of the project more complex than before (Bosch-Rekveldt et al., 2015). Today, projects are often used in more advanced technologies, the scope and dimensions of projects have increased, projects have extended supply chains, the number of beneficiaries of projects has increased. These complexities have led organizations to often fail to complete projects within a set time frame, approved by the budget, and in accordance with the quality required. In other words, projects in recent years have often failed or have poor performance in achieving their goals (Giezen et al., 2015; Gransberg et al., 2012; He et al., 2015). Under such circumstances, the traditional project management practices that have been used up so far are no longer able to control the emerging complexity of the projects (Li et al., 2015). In the traditional framework of project management, only the usual dimensions of a project, such as time, cost, and quality, are considered. In newer project management models, there are a number of other aspects, including risks and project changes. However, as projects become more complex, these dimensions alone cannot fully describe the behavior of a project (Müller \& Turner, 2010; Sadi-Nezhad et al., 2013). In fact, one of the important features of the projects that plays a major role in the failure and success of the project and can be one of the sources of new risks in the projects is the complexity of the project. According to Awad and Fayek (2012), "In the construction bonding business, a complex and comprehensive prequalification or assessment process is done to evaluate contractor, project, and contractual risks".

Fortunately, in recent years, many scholars have discovered the importance of discussing the complexity of the new project management and attempted to identify the various aspects of the complexity of the project and provide the right solutions for them (Lu et al., 2015). However, the maturity of project management science in terms of complexity is still very low and, compared to other areas of project management knowledge, it has not been sufficiently advanced. Most of the studies in this regard only provided some basic conceptual models or identified a number of complexity factors in the project. Therefore, more studies and efforts are needed to provide a comprehensive framework for integrated complex project management and control (Lessard et al., 2014).

In addition, another major factor in the success of projects is the allocation of a suitable project manager, but the allocation of the most qualified project manager can be a major challenge, due to the many dimensions that must be considered. Using an inappropriate project manager, without the knowledge and experience required, he /she could threaten the success of a project, since he/she probably would not be able to fully manage the project in all its aspects. Many studies have been conducted on the suitability of project managers and the selection of appropriate project manager. In most of these studies, the amount and type of complexity of the project have been mentioned as factors influencing the design of an appropriate project manager. However, so far, there has not been any specific approach for assigning the project manager to the complexity of the project. Therefore, in this research, we try to study the relationship between the complexity of the project and the merits of the project manager by developing and applying a structural equation modeling approach (Senescu et al., 2012).

This research has been accomplished in four main steps. In the first step, a comprehensive overview of the literature on the complexity of the project is addressed. Also in this step, other research on the eligibility criteria of the project manager is reviewed. Accordingly, the proposed classification structure for project complexities, project managers' competencies and relationships between competence criteria and complexity factors are described. In the second step, the proposed approach, i.e., modeling structural equations for identifying and analyzing the relationships between the complexity factors of the project and the criteria for the competence of the project manager is presented. In the third step of 
the research, validation and measurement of the system's efficiency is demonstrated by conducting a case study on a number of power plant construction projects. In the final stage, the results and achievements of the research as well as the proposed future studies are summed up.

\section{Literature review}

Organizations are always looking for good project managers to guide their project activities. These days, there are many different definitions of the concept of merit. International Project Management Association (2006) describes merit as a set of knowledge, individual attitudes, skills and experiences that are needed to succeed in a particular function. It also describes competence as a proven ability to carry out activities in a project environment that results in expected results in accordance with defined and accepted standards. A project manager needs to have a series of merit criteria for a specific project, so that the project can be successfully completed. The competencies required for a project manager must be changed according to factors such as the type and characteristics of the project. In fact, it is also necessary that potential differences in the importance of specific competencies for a particular type or specific features of a project be considered while applying a project manager's suitability model. Afshari (2015) developed a systematic method in order to determine the best candidate for construction project manager selection by applying Delphi method and fuzzy linguistic evaluation (Kauffman \& Gupta, 1991; Afshari et al., 2013; Bojadziev \& Bojadziev, 2007; Ross, 2009; Xu \& Lin, 2016) and also validated the method using a case study of construction project manager selection in a project based company. Ahsan et al. (2013) investigated the competencies organizations use through project manager job advertisements. They proposed a comprehensive list of project manager job competencies; break down the competency components (Liyana Othman \& Jaafar, 2013; Safarzadegan Gilan et al., 2012) into knowledge, skills, and abilities; and conduct a comparative analysis of the implementation of these competencies.

Chao and Hsiao (2012) presents a data-clustering-based fuzzy framework (Dubois \& Prade, 1978; Chen \& Hwang, 1992) for forecasting the performance of construction projects delivered through various procurement methods. Chou et al. (2008) provided a fuzzy multiple attributes decision-making method called fuzzy simple additive weighting system, for handling facility location selection problems by applying objective/subjective attributes under group decision-making circumstances.

Ebrahimnejad et al. (2014) investigated the relative importance of risk ranking in mega projects by applying fuzzy compromise programming methods. Fisher (2011) investigated what project management practitioners could consider to be skills and behaviors of an effective people project manager. They suggest that project managers could benefit from adopting these skills and behaviors to strengthen their managing people skills and behaviors to improve the successful delivery of projects.

Many companies have applied different initiatives such as outsourced manufacturing which normally makes a supply chain (SC) more vulnerable to different kinds of disruptions. Therefore, managing risk is a critical component of SC management. Various kinds of SC vulnerability management methodologies have been proposed for managing SC risk, most offer only point-based solutions that deal with a limited set of risks. Moeinzadeh and Hajfathaliha (2009) aimed to reinforce SC risk management by planning an integrated approach. SC risks were detected and a risk index classification structure was built. They developed a SC risk assessment approach based on the analytic network process (ANP) and the VIKOR methods under the fuzzy environment where the vagueness and subjectivity were treated with linguistic terms parameterized by triangular fuzzy numbers. Nguyen et al. (2015) tried to quantify the complexity of transportation projects by applying the fuzzy analytic hierarchy process. Qureshi and Kang (2015) analyzed the organizational factors of project complexity by applying structural equation modelling. Sadeghi et al. (2014) performed an assessment by evaluating project managers using an interval decision-making method based on a new project manager competency model. 
Shahhosseini and Sebt (2011) presented a fuzzy adaptive decision making model for choosing various kinds of competent personnel. They classified human resources into four kinds of main personnel: Project Manager, Engineer, Technician, and Laborer and developed the competency criteria model of each main personnel. The proposed model integrated a fuzzy logic qualitative method and neural network adaptive capabilities to make an assessment on construction personnel based on their competency. Sun et al. (2015) performed a comprehensive study on BIM-based construction project cost and schedule risk early warning. Tah and Carr (2000) presented a framework for construction project risk assessment using fuzzy logic. Varajão and Cruz-Cunha (2013) applied analytical hierarch process and the IPMA competence baseline in the project managers selection process. Vidal et al. (2013) and Xia and Chan (2012) constructed a project complexity framework based on an international Delphi study. YazdaniChamzini et al. (2013) developed a fuzzy model based on subtractive clustering for road header performance prediction. Zhang et al. (2013) identified the key social competencies for Chinese construction project managers.

\section{The proposed method}

In the initial part of this research, we tried to highlight the importance of the complexity issue in project management. In short, we conclude that undoubtedly complexity is one of the main obstacles in achieving predetermined goals of projects. It was then mentioned that in order to control the complexity of the project and reduce its negative effects, the complexity of a project should first be evaluated. The first step in this direction is to identify the key elements of complexity in projects. For this purpose, a comprehensive literature review was conducted in the previous section, and the main contributors to the complexity of the project, presented in recent years by other researchers. Now, in this section, we will outline the proposed structure to classify the complexity of the project.

Of course, the complexity of the project is very wide and we can categorize these factors in a variety of ways. According to some other studies, it can be concluded that the complexity of the project comes from four main sources: organization, characteristics, resources and environment. It is also possible to categorize the complexity of the project based on internal and external aspects, or aspects that can be controlled and uncontrollable. The first category stems from the complexity of the project from the organization. More precisely, these factors relate to how to organize, manage, and plan a project. It is clear that the organizational factors are internal and controllable. This means that they can improve their status, some of which include: the number of hierarchical levels, reporting frequencies, and interdependencies of information systems. Another inherent source of complexity is the inherent characteristics of a project, such as: the size of the project budget, the number of items to be delivered and the newness of the project. Unlike the first group, these kinds of complexity factors are uncontrollable and we are not able to modify or remove them.

The third category is the complexity of the resource-related project, which is considered as an exogenous source of complexity of the project. Just like an organization, these origins can be controlled. For example, the geographic dispersion of the project team members, the number of new contractors and the degree of external resource integrity can be noted. The ultimate origin of the complexity of the project is the environment. Anything that is affecting a project is called a project environment. Obviously, external environmental factors are beyond our control, for example: multiple stakeholders with conflicting expectations, market competition, and geological and climatic conditions.

In addition to identify the origins of the complexity of the project, it is necessary to identify the causes of the complexity of the project. By examining the complexities identified by the literature review, six major reasons for the complexity of the project were identified, including: multiplicity, diversity, interdependence, size, novelty, and lack of utility. Multiplicity means having a large number of components, parts or sections, such as: the number of contracts or packages, the number of activities and the number 
of identified risks. Diversity refers to the various types of components, sectors or parts, such as: Various capital resources, different nationalities of the project team members, and diverse project objectives.

Interdependence means the existence of a two-way relationship between the components, the parts or the parts, and their effect on each other. Examples include relationships between tasks, interdependencies between organizational units and interrelationships between the project phases. Another reason for the complexity of a project is size, which refers to criteria such as magnitude, volume, distance, and severity. The duration of the project, the levels of risks and the range of contracts are examples of size. Novelty refers to the new and unknown for project managers, in other words, impoverishment and lack of maturity, such as: new employer, the use of new technology, and the inexperience of members of the project team.

Inappropriate and inappropriate conditions in the project are meant to be desirable. Disadvantages include such criteria as: conflict, coexistence, lack of transparency, lack of integrity, flexibility, lack of cooperation, incompatibility and inaccessibility. For example, difficult communications, compact scheduling, and inadequate employer support. Multiplicity, diversity, interdependence, and size are quantitative measures that are measurable numerically. In contrast, novelty and inadequacy are qualitative criteria that cannot be quantified quantitatively and precisely.

\subsection{Sample data}

The statistical population of this study includes all the 95 experts of the study company who had more than 10 years of experience. These people had either a history of membership in the project team or were senior project managers. The method of sampling in this research is random and based on the Cochran formula for determining the sample size. Therefore we could use the following formula to calculate the minimum number of sample size,

$$
n=\frac{N \times z_{\alpha / 2}^{2} \times p \times q}{\varepsilon^{2} \times(N-1)+z_{\alpha / 2}^{2} \times p \times q},
$$

where $N$ is the population size, $p=1-q$ represents the yes/no categories, $z_{\alpha / 2}$ is CDF of normal distribution and finally $\varepsilon$ is the error term. Since we have $p=0.5, z_{\alpha / 2}=1.96$ and $N=95$, the number of sample size is calculated as $n=76$.

In this research, the data gathering tool consists of three questionnaires. The first questionnaire is about assessing the complexity of the project, which has 36 questions. These questions are characterized by the score that subjects on the Likert scale given to this questionnaire. Complexity of the project has 12 components related to various factors of complexity of the project. The second questionnaire was about the evaluation of the level of competence of the project manager with 36 questions. These questions are characterized by the score that subjects on the Likert scale given to this questionnaire. The project manager also has 12 components related to the various criteria of the project manager's suitability. The third questionnaire was the evaluation of the success rate of the project, which has 27 questions. The project success has 5 components related to project performance, impact on the customer or the user, the impact on the project team, organizational and business success, and preparation for the future.

\subsection{Validity and Reliability}

The measurement tool must have the necessary validity and reliability so that the researcher can collect the appropriate data and, through the data and analysis, test the hypotheses and answer the research questions. The test validity refers to the ability of the tool to measure the attribute that the test was designed to measure. If the means of collecting information is not sufficiently comprehensive and cannot properly measure all that is considered by the researcher, or it cannot hinder the measurement of 
what we do not want to be measured, then the results are far from will be true. In order to prevent this problem, the scientific credibility of the questionnaire should be considered. Although the questionnaire design was based on standard questionnaires, in order to guarantee the validity of the questionnaires, the comments of 5 project management experts were selected to remove and modify some research questions. Accordingly, after calculations, using the content validity method, the validity of the questionnaire for evaluation of the complexity of the project, the evaluation of the level of competence of the project manager and the evaluation of the success rate of the project were determined to be 0.85 , 0.81 and 0.83 , respectively. Since the values of the validity of these questionnaires are higher than 0.70 , their validities are confirmed.

Reliability which points to the accuracy, reliability and stability of the test results. One of the technical characteristics of the instrument is the measurements and states that the measuring instrument under the same conditions obtains the same results. Also, the reliability coefficient indicates how much the tool measures the stable characteristics or characteristics of the subject's variables. In this study, Cronbach's alpha method was used to measure the reliability of the questionnaire. The correlation coefficient of Cronbach's alpha is a value between zero and one. If there is a stable questionnaire, the Cronbach's alpha coefficient is greater than 0.7 , and the closer it is to one, the questionnaire is more reliable. Accordingly, after calculating, using Cronbach's alpha method, the internal consistency or reliability of the project evaluation complexity assessment questionnaires, the evaluation of the project manager's competence level and the evaluation of the project success rate were $0.893,0.818$ and 0.869 were determined, respectively. These values are acceptable for research purposes (greater than 0.70). It should be noted that the sample size was 30 for the reliability of the questionnaires.

One of the most important stages in the research is the stage of analyzing statistical data. Using the correct statistical methods enables the presentation of the correct results. This phase consists of two major parts, describing the data and analyzing the data. In the data analysis section, the hypotheses and research questions were investigated, using a partial least squares approach (PLS). Before testing the hypotheses, the normalization (natural distribution of the variables) of the studied variables was investigated by Kolmogorov-Smirnov test (K-S). It should be noted that in this study, a significant level of 0.05 was considered and all the studies were performed on the basis of 75 subjects.

\subsection{Personal characteristics of the sample size}

In this section, descriptions of demographic characteristics and variables of research are presented. At first, descriptions of demographic indicators (gender, marital status, age, education, and service record) have been addressed. According to the results of this study, out of 75 participants in this study, 69 (92\%) were male and $6(8 \%)$ were female, $51(68 \%)$ were married and $24(32 \%)$ were single, 20 partcipants (26\%) were less than 30 years old, 31 (42\%) were between 31 and 40 years old, and 24 $(32 \%)$ were more than 41 years old, 3 (4\%) had undergraduate and lower education, $49(65 \%)$ undergraduate and $23(31 \%)$ undergraduate and higher; $14(19 \%)$ had a service record of less than 10 years; $45(60 \%)$ were between 11 and 20 years; and $16(21 \%)$. More than 21 years old.

Given that the values of sloping and elongation are in the range $(-2,2)$, then the data is not far from normal distribution. In addition to descriptive indexes for the research variables, the scores derived from the mean of questions related to the dimensions of the variables under study were divided into five categories in order to provide a qualitative descriptor of these variables.

In this section, partial least squares (PLS) approach was used to investigate more precisely the research hypotheses. This is done in two steps, including testing the model of measurement and testing the fit of the structural model. Validity of indices is investigated by factor load, which is the factor that should be more than 0.4 so that it can be validated and considered as a question that measures our index. In the absence of this issue, it should identify the inappropriate questions and dimensions and improve the 
model by eliminating the questions that have caused them to reduce the burden. Also, for fitting measurement models, Cronbach's alpha, combined reliability (CR), extracted mean variance (AVE), convergent validity, and divergent validity are used. As shown in Table 1, the Cronbach's alpha and the combined reliability of the research variables are more than 0.7 , which indicates the proper reliability of the research variables. Convergent validity examines the degree of correlation of each structure with its questions (indexes). Conversely, divergent validity is examined by comparing the correlation of a structure with its indexes against the correlation of that structure with other structures. The results of divergent validity measurements for the research variables presented in Table 2 show the suitability of the model.

\section{Table 1}

Cronbach's alpha, combined reliability and AVE for the variables studied

\begin{tabular}{lccc}
\hline Variable & Cronbach Alpha & Combined validity & AVE \\
\hline Project complexity & 0.877 & 0.896 & 0.571 \\
Project manager's competency & 0.839 & 0.87 & 0.533 \\
Project success & 0.845 & 0.873 & 0.508 \\
\hline
\end{tabular}

\section{Table 2}

A divergent validity study for the variables studied

\begin{tabular}{lccc}
\hline Variable & Project complexity & Project manager's competency & Project success \\
\hline Project complexity & 0.686 & & \\
Project manager's competency & 0.432 & 0.659 & 0.638 \\
Project success & 0.208 & 0.413 & \\
\hline
\end{tabular}

In some cases, the researcher encounters a moderator variable in examining the relationship between the two variables and needs to examine the effect of this moderator variable on the relationship between the two main variables. The moderator modulates the direction or severity of the relationship between the independent and dependent variable by modifying (low or high). The difference in plotting models containing a modulator variable is that these models are not depicted in the same way as their conceptual model. In the PLS method, to examine the effect of a modulator variable, a new variable is added in the role of interactive effect between the main independent variable and the modulator variable of the model. According to the model, the factor loads that are less than 0.4 are eliminated, so that other criteria are not affected by them. Here, given that none of the questions about model variables with factor loadings are less than 0.4, they are not excluded from the model. Fig. 1 shows executed model with factor load coefficients.

\subsection{Hypothesis of the survey}

The main hypothesis 1 states that there is a meaningful relationship between the complexity of the project and the success of the project. The significant $\mathrm{Z}$ coefficient between the variables of the complexity of the project and the project success is 10.254 , which is more than 1.96 , indicating the complexity of the project and the success of the project. Also, the standardized coefficient of the path between the variables of the complexity of the project and the project success is 0.491 , which indicates the direct relationship between these two variables, indicating that the complexity of the project directly explains $49 \%$ of the project's success changes.

The main hypothesis 2 states that there is a meaningful relationship between the complexity of the project and the success of the project, given the moderator role of the project manager's competence. In this study, the $\mathrm{Z}$ significant coefficient related to the project complexity variable. The project manager's suitability is calculated to be 4.301 , which, indicates that at the 95 confidence level it is possible to validate the impact of the project manager's suitability variable as a moderator variable. In other words, it can be confirmed at $95 \%$ confidence level that the manager's eligibility variable modifies the relationship between project complexity and project success. The competence of the project manager 
and the success of the project was 0.366 , indicating that the project manager's suitability variable, the relationship between the complexity of the project and the success Reduces the project.

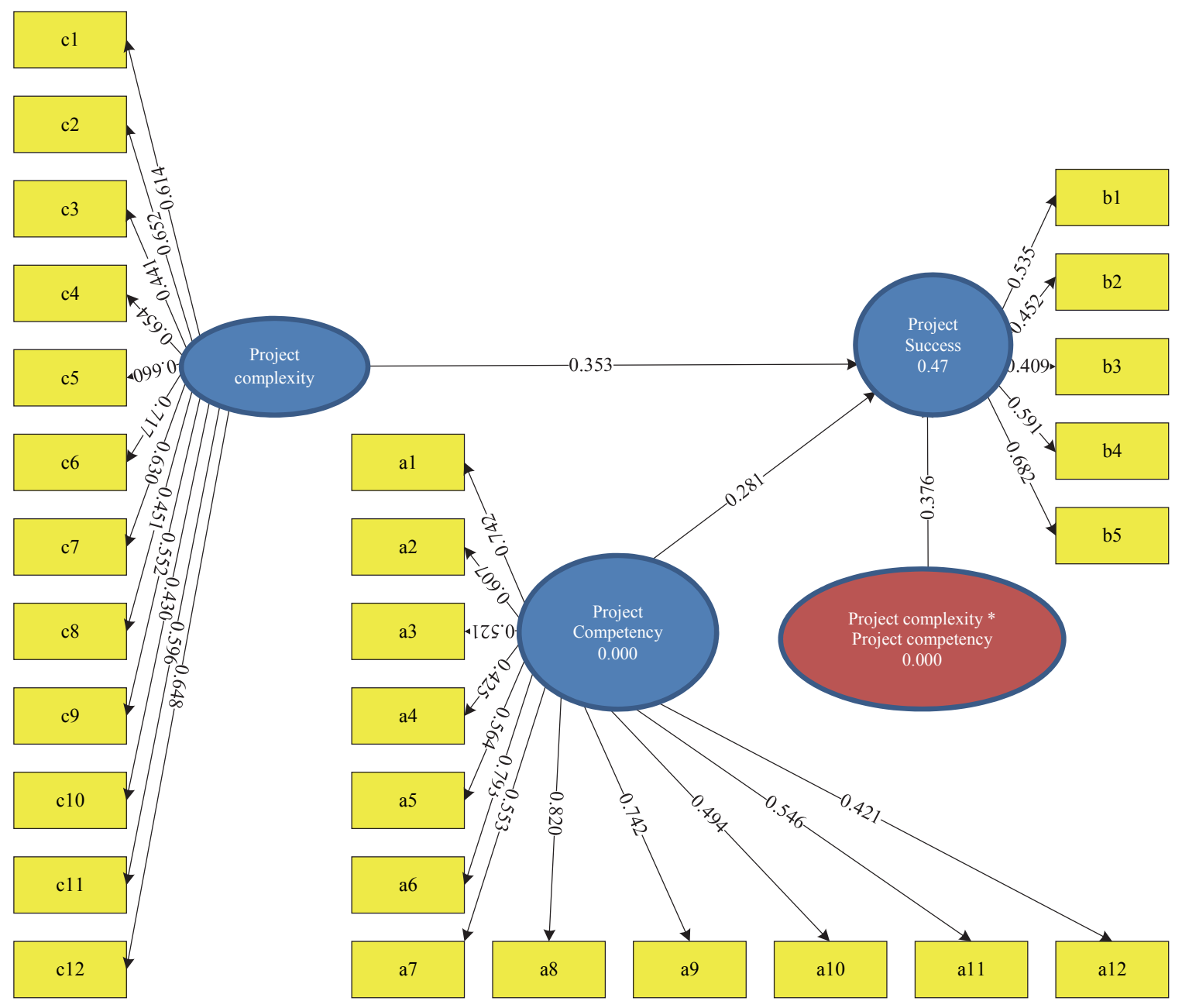

Fig. 1. Executed model with factor load coefficients

Sub-hypothesis 1 states that there is a meaningful relationship between the complexity of the project organization and the success of the project, given the moderator role of managerial competence of the project manager (See Fig. 1). The Z significant factor is related to the complexity variable of the project organization. Managerial competence of the project manager, is 5.443, which, shows that at the level $95 \%$ confidence can be confirmed by the impact of the managerial suitability variable of the project manager as a moderator variable. In other words, it can be confirmed at $95 \%$ confidence level that the manager's managerial variable of the project modifies the relationship between the complexity of the project organization and the project's success. The managerial competence of the project manager and the project success is 0.266 , indicating that the manager's managerial variable of the project reduces the relationship between the complexity of the project organization and the project success.

Sub-hypothesis 2 states that there is a meaningful relationship between the complexity of the project and the success of the project, due to the moderator role of the knowledge competence of the project manager (See Fig. 2). The knowledge competence of the project manager is 3.410 which, shows that at $95 \%$ confidence level, the impact of the knowledge competence variability of the project manager can be as modifier variable approved. In other words, it can be confirmed at $95 \%$ confidence level that the project's knowledge competence variables modify the relationship between the inherent complexity 
of the project and the project's success. The knowledge competence of the project manager and the project success is 0.397 and indicates that the knowledge competence variable of the project manager, the relationship between complexity it reduces the intrinsic nature of the project and the success of the project.

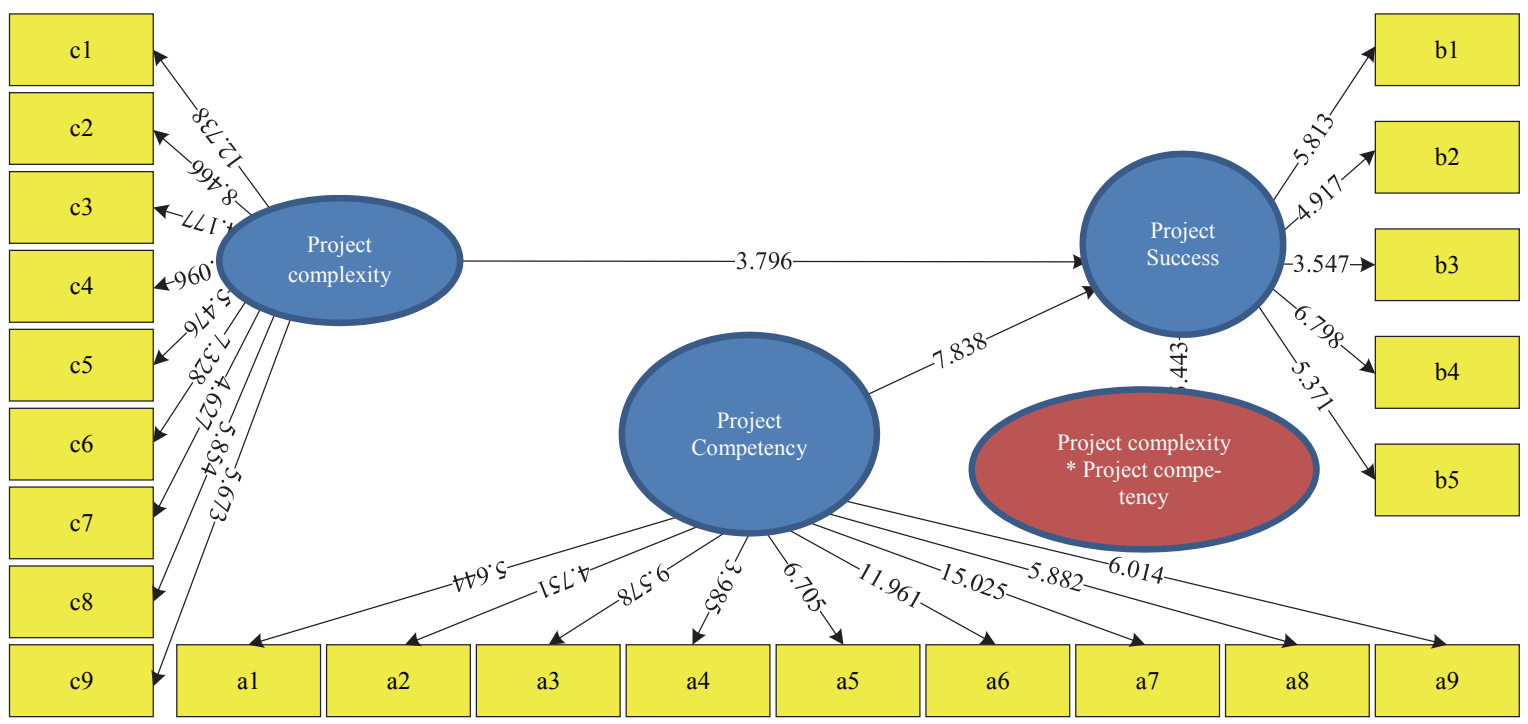

Fig. 2. The relationship between organizational complexity and project success with a moderating role of managerial competence along with meaningful coefficients $\mathrm{Z}$

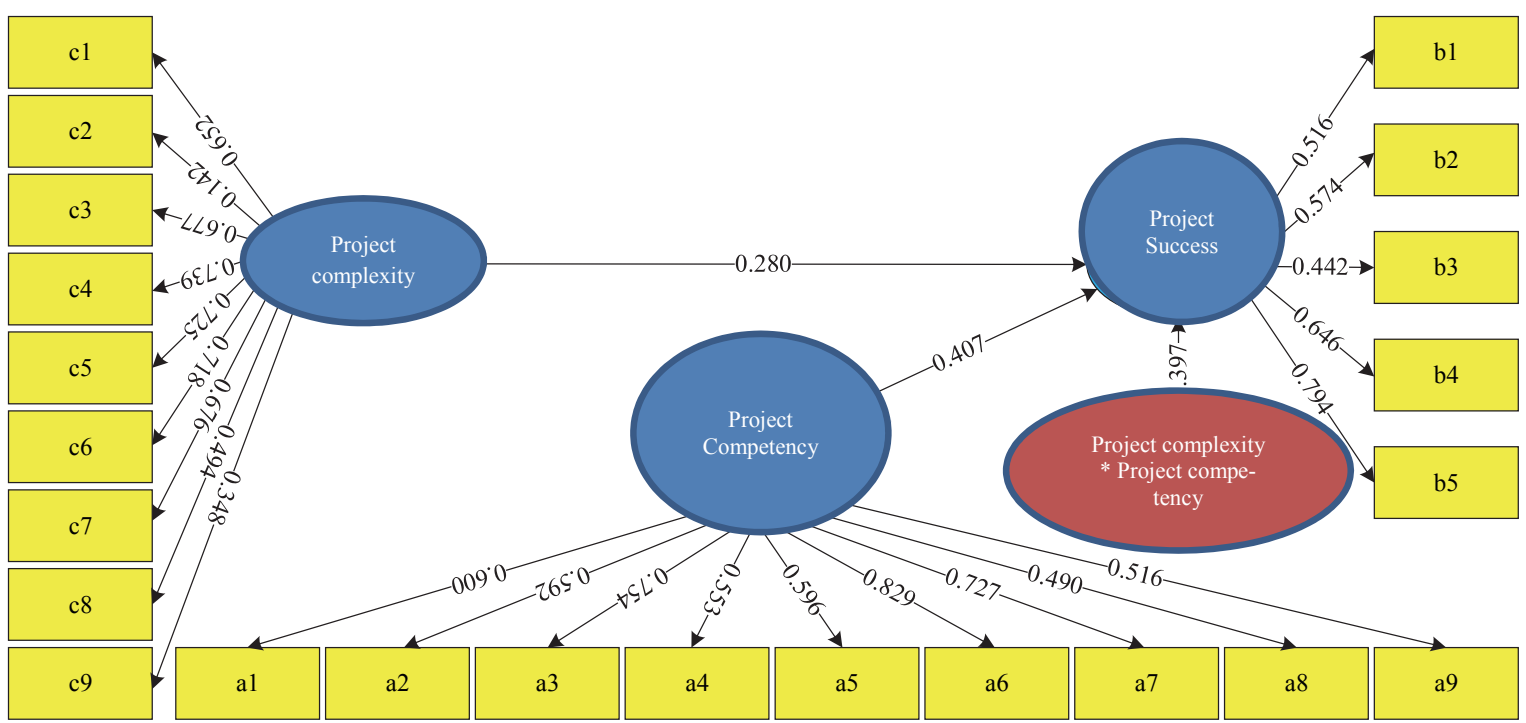

Fig. 3. The relationship between inherent complexity and project success with the role of moderating knowledge competence along with standardized coefficients

Sub-hypothesis 3 states that there is a meaningful relationship between the complexity of the project's resources and the success of the project, given the moderator role of the functional competence of the project manager (See Fig. 3). The functional competence of the project manager has been calculated to be 2.765 which, indicates that at $95 \%$ confidence level, the functional suitability variable of the project manager modifies the relationship between the complexity of the project resources and the success of the project. The project manager's performance and project success rate is 0.325 , indicating that the project manager's functional suitability variable reduces the relationship between the complexity of project resources and the success of the project. 


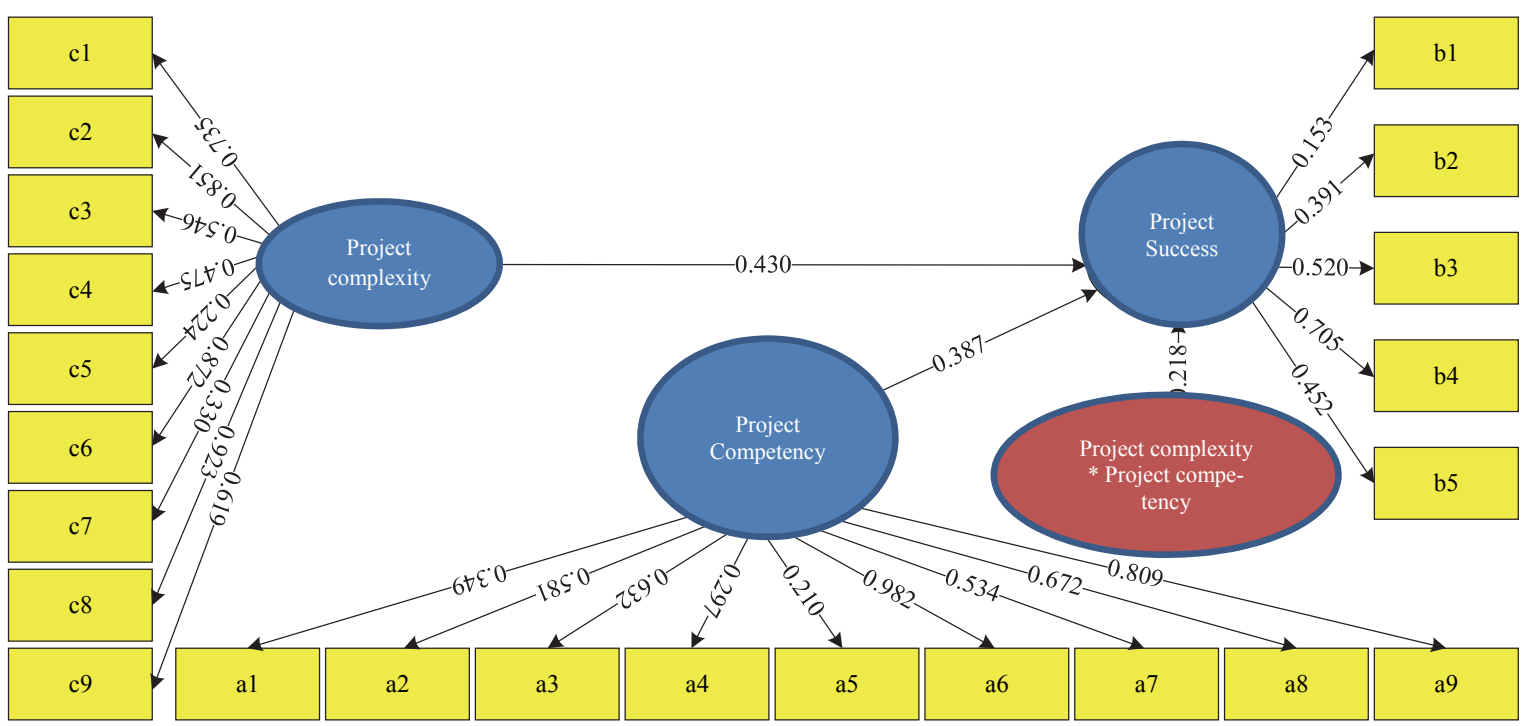

Fig. 4. Relationship between the complexity of the environment and the success of the project with the role of behavioral moderation, along with standardized coefficients

Sub-hypothesis 4 states that there is a meaningful relationship between the complexity of the project environment and the success of the project, given the role of moderator of the behavioral competence of the project manager (Fig. 4). The behavioral competence of the project manager has been calculated to be 3.641 , which shows that at $95 \%$ confidence level, the behavioral competence variable of the project manager correlates the relationship between the complexity of the project environment and the success of the project.

\section{Conclusion}

Project management is a critical task that needs the best people for this responsibility. The allocation of the most qualified project manager is a complex subject, because there are many issues that need to be addressed. Recently, complexity management has become another important aspect of project management, which should be carefully considered. Therefore, in this research, the issue of the structure of relationships between the complexity of the project and the criteria of the merit of the project manager have been examined. The methodology and process developed in this study were based on a structural equation modeling approach. Compared with previous research, this study has several innovations in the methodology of project managers' competence assessment. This research has contributed greatly to the knowledge of this field by adopting a comprehensive approach, modeling structural equations to examine the issue of project manager selection in view of the complexity of the project.

This research does not limit the merit of project managers to ranking only project managers. Instead, it involves identifying the eligibility criteria of the project managers and the complexity of the projects. From a practical point of view, as a direct result of this paper, a set of twelve specific criteria for the suitability of the project manager and the complexity of the project related to them have been presented. These twelve indicators represent the general criteria for assessing the competence of project managers based on the complexity of the projects. In this paper, the ability to control the complexity of the project is provided by selecting an appropriate project manager. In this regard, the assigned project manager must obtain an acceptable level of competence in relation to each of the complexity factors of the project. Otherwise, the status of related qualifications will be improved or strengthened to increase the level of competence of the project manager. Consequently, this feature makes it possible to align the decisions of the project manager with the project field. Also, decision makers of the organization can capture this knowledge and information about the complexity of the project and the suitability of the project manager for future use in the system. The proposed process should be continually reviewed 
throughout the life cycle of the project in order to be aware of the changes in the complexity of the project and the suitability of the project manager. Therefore, future studies can develop a computer software that continuously evaluates the complexity of the project and the competencies of the project manager in order to keep up-to-date control and continuous improvements in project management. As a further step for this research, we can develop the method presented in this study and, in order to analyze the selection issues of the project manager in other companies and other types of projects.

\section{References}

Afshari, A., Yusuff, R., \& Derayatifar, A. (2013). Linguistic extension of fuzzy Integral for Group Personnel Selection Problem. Arabian Journal for Science \& Engineering (Springer Science \& Business Media $B V), 38(10)$.

Afshari, A. (2015). Selection of construction project manager by using Delphi and fuzzy linguistic decision making. Journal of Intelligent \& Fuzzy Systems, 28(6), 2827-2838.

Ahadzie, D. K., Proverbs, D. G., \& Sarkodie-Poku, I. (2014). Competencies required of project managers at the design phase of mass house building projects. International Journal of Project Management, 32(6), 958-969.

Ahsan, K., Ho, M., \& Khan, S. (2013). Recruiting project managers: A comparative analysis of competencies and recruitment signals from job advertisements. Project Management Journal, 44(5), 36-54.

Awad, A., \& Fayek, A. R. (2012). A decision support system for contractor prequalification for surety bonding. Automation in Construction, 21, 89-98.

Bojadziev, G., \& Bojadziev, M. (2007). Fuzzy logic for business, finance, and management.

Bosch-Rekveldt, M., Bakker, H., Hertogh, M., \& Mooi, H. (2015). Drivers of complexity in engineering projects. In Handbook on Project Management and Scheduling Vol. 2 (pp. 1079-1101). Springer International Publishing.

Chao, L. C., \& Hsiao, C. S. (2012). Fuzzy model for predicting project performance based on procurement experiences. Automation in Construction, 28, 71-81.

Chen, S. J., \& Hwang, C. L. (1992). Fuzzy multiple attribute decision making methods. In Fuzzy multiple attribute decision making (pp. 289-486). Springer, Berlin, Heidelberg.

Chou, S. Y., Chang, Y. H., \& Shen, C. Y. (2008). A fuzzy simple additive weighting system under group decision-making for facility location selection with objective/subjective attributes. European Journal of Operational Research, 189(1), 132-145.

Dubois, D., \& Prade, H. (1978). Operations on fuzzy numbers. International Journal of systems science, 9(6), 613-626.

Ebrahimnejad, S., Mousavi, S. M., Tavakkoli-Moghaddam, R., \& Heydar, M. (2014). Risk ranking in mega projects by fuzzy compromise approach: A comparative analysis. Journal of Intelligent \& Fuzzy Systems, 26(2), 949-959.

Fisher, E. (2011). What practitioners consider to be the skills and behaviours of an effective people project manager. International Journal of Project Management, 29(8), 994-1002.

Giezen, M., Bertolini, L., \& Salet, W. (2015). Adaptive capacity within a mega project: A case study on planning and decision-making in the face of complexity. European Planning Studies, 23(5), 999-1018.

Gransberg, D. D., Shane, J. S., Strong, K., \& del Puerto, C. L. (2012). Project complexity mapping in five dimensions for complex transportation projects. Journal of Management in Engineering, 29(4), 316-326.

He, Q., Luo, L., Hu, Y., \& Chan, A. P. (2015). Measuring the complexity of mega construction projects in China-A fuzzy analytic network process analysis. International Journal of Project Management, 33(3), 549-563.

International Project Management Association, \& Caupin, G. (2006). IPMA competence baseline: ICB; Version 3.0. Internat. Project Management Association.

Kahraman, C. (Ed.). (2008). Fuzzy multi-criteria decision making: theory and applications with recent developments(Vol. 16). Springer Science \& Business Media.

Kauffman, A., \& Gupta, M. M. (1991). Introduction to Fuzzy Arithmetic, Theory and Application.

Lessard, D., Sakhrani, V., \& Miller, R. (2014). House of Project Complexity—understanding complexity in large infrastructure projects. Engineering Project Organization Journal, 4(4), 170-192.

Li, Y., Lu, Y., Kwak, Y. H., \& Dong, S. (2015). Developing a city-level multi-project management information system for Chinese urbanization. International Journal of Project Management, 33(3), 510-527.

Lin, K. L. (2010). Human resource allocation for remote construction projects. Journal of Management in Engineering, 27(1), 13-20. 
Lu, Y., Luo, L., Wang, H., Le, Y., \& Shi, Q. (2015). Measurement model of project complexity for large-scale projects from task and organization perspective. International Journal of Project Management, 33(3), 610622.

Moeinzadeh, P., \& Hajfathaliha, A. (2009). A combined fuzzy decision making approach to supply chain risk assessment. World Academy of Science, Engineering and Technology, 60(2), 519-528.

Müller, R., \& Turner, R. (2010). Leadership competency profiles of successful project managers. International Journal of Project Management, 28(5), 437-448.

Nguyen, A. T., Nguyen, L. D., Le-Hoai, L., \& Dang, C. N. (2015). Quantifying the complexity of transportation projects using the fuzzy analytic hierarchy process. International Journal of Project Management, 33(6), 1364-1376.

Nguyen, H. T., \& Walker, E. A. (2005). A first course in fuzzy logic. CRC press.

Liyana Othman, N., \& Jaafar, M. (2013). Personal competency of selected women construction project managers in Malaysia. Journal of Engineering, Design and Technology, 11(3), 276-287.

PMI Standards Committee. (2002). Project manager competency development (PMCD) framework. Project Management Institute (PMI), Newtown Square, Pennsylvania.

Qureshi, S. M., \& Kang, C. (2015). Analysing the organizational factors of project complexity using structural equation modelling. International Journal of Project Management, 33(1), 165-176.

Ramasesh, R. V., \& Browning, T. R. (2014). A conceptual framework for tackling knowable unknown unknowns in project management. Journal of Operations Management, 32(4), 190-204.

Ross, T. J. (2009). Fuzzy logic with engineering applications. John Wiley \& Sons.

Sadeghi, H., Mousakhani, M., Yazdani, M., \& Delavari, M. (2014). Evaluating project managers by an interval decision-making method based on a new project manager competency model. Arabian Journal for Science \& Engineering (Springer Science \& Business Media BV), 39(2).

Sadi-Nezhad, S., Noroozi-yadak, A., \& Makui, A. (2013). Fuzzy distance of triangular fuzzy numbers. Journal of Intelligent \& Fuzzy Systems, 25(4), 845-852.

Safarzadegan Gilan, S. S., Sebt, M. H., \& Shahhosseini, V. (2012). Computing with words for hierarchical competency based selection of personnel in construction companies. Applied Soft Computing, 12(2), 860-871.

Senescu, R. R., Aranda-Mena, G., \& Haymaker, J. R. (2012). Relationships between project complexity and communication. Journal of Management in Engineering, 29(2), 183-197.

Shahhosseini, V., \& Sebt, M. H. (2011). Competency-based selection and assignment of human resources to construction projects. Scientia Iranica, 18(2), 163-180.

Sorooshian, S., Afshari, A., \& Dodangeh, J. (2014). Linguistic extension for group multicriteria project manager selection. Journal of Applied Mathematics. 14(1), 1-8.

Sun, C., Man, Q., \& Wang, Y. (2015). Study on BIM-based construction project cost and schedule risk early warning. Journal of Intelligent \& Fuzzy Systems, 29(2), 469-477.

Tah, J. H. M., \& Carr, V. (2000). A proposal for construction project risk assessment using fuzzy logic. Construction Management \& Economics, 18(4), 491-500.

Varajão, J., \& Cruz-Cunha, M. M. (2013). Using AHP and the IPMA competence baseline in the project managers selection process. International Journal of Production Research, 51(11), 3342-3354.

Vidal, L. A., Marle, F., \& Bocquet, J. C. (2013). Building up a project complexity framework using an international Delphi study. International Journal of Technology Management, 62(2/3/4), 251-283.

Xia, B., \& Chan, A. P. (2012). Measuring complexity for building projects: a Delphi study. Engineering, Construction and Architectural Management, 19(1), 7-24.

$\mathrm{Xu}, \mathrm{F}$., \& Lin, S. P. (2016). Theoretical framework of Fuzzy-AI model in quantitative project management. Journal of Intelligent \& Fuzzy Systems, 30(1), 509-521.

Yazdani-Chamzini, A., Razani, M., Yakhchali, S. H., Zavadskas, E. K., \& Turskis, Z. (2013). Developing a fuzzy model based on subtractive clustering for road header performance prediction. Automation in Construction, 35, 111-120.

Zhang, F., Zuo, J., \& Zillante, G. (2013). Identification and evaluation of the key social competencies for Chinese construction project managers. International Journal of Project Management, 31(5), 748-759.

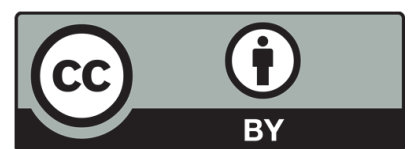

(C) 2018 by the authors; licensee Growing Science, Canada. This is an open access article distributed under the terms and conditions of the Creative Commons Attribution (CC-BY) license (http://creativecommons.org/licenses/by/4.0/). 